\title{
Urodynamic profile in the Department of Urology, Cipto Mangunkusumo Hospital between 2010 and 2015
}

Angling Yunanto, Harrina Erlianti Rahardjo

pISSN: 0853-1773 • elSSN: 2252-8083 https://doi.org/10.13181/mji.v28i2.1666 Med J Indones. 2019;28:146-53

Received: February 25, 2017

Accepted: April 01, 2019

Authors' affiliations: Department of Urology, Faculty of Medicine, Universitas Indonesia, Cipto Mangunkusumo Hospital, Jakarta, Indonesia

\section{Corresponding author:}

Harrina Erlianti Rahardjo Department of Urology, Cipto Mangunkusumo Hospital, Jalan Diponogoro No. 71, Kenari, Senen, Central Jakarta 10310, DKI Jakarta, Indonesia

Tel/Fax: +62-21-3152892/+62-21-

3145592

E-mail: harrinaerlianti@gmail.com

\begin{abstract}
BACKGROUND This study was aimed to describe urodynamic profiles, the role and advantages of urodynamics for urinary problems detection, and to analyze whether urodynamic examination has been ordered based on accurate indications following guidelines in the Department of Urology Cipto Mangunkusumo Hospital between 2010 and 2015 .
\end{abstract}

METHODS Data was retrieved from the patient's medical records who underwent urodynamic examinations in the Department of Urology Cipto Mangunkusumo Hospital between July 2010 to August 2015.

RESULTS Total of 1,091 patients undergone urodynamic procedures in the Department of Urology Cipto Mangunkusumo Hospital. In 553 lower urinary tract symptoms (LUTS) patients, there were 186 (34\%) small bladder capacity, 84 (15\%) detrusor overactivity (DO), 180 (33\%) bladder outlet obstruction (BOO), and 198 (36\%) bladder atony patients. In the 317 urinary retention patients, there were 121 (38\%) patients with $\mathrm{BOO}$ and $2(1 \%)$ patients with a normal voiding phase. In 80 overactive bladder patients, there were 51 (64\%) with DO, 17 (21\%) with DO incontinence, and 22 (28\%) with urodynamic stress incontinence (SI). Among 81 patients with SI problems, there were $63(78 \%)$ urodynamic SI, $9(11 \%)$ DO, and 9 (11\%) DO incontinence patients. In 60 (6\%) pediatric patients, most LUTS and urinary retention patients were caused by impaired bladder contraction.

CONCLUSIONS This study shows the role and superiority of urodynamics in diagnosing patients with voiding disorders, especially if with mixed components in it. Urodynamics played essential roles in detecting urinary problems at Cipto Mangunkusumo Hospital.

KEYWORDS detrusor underactivity, lower urinary tract symptoms, overactive bladder, urodynamics, voiding disorder
Micturition problems are one of the most common problems in urology. In England, approximately $20 \%$ of urogynecology patients complain about their micturition. ${ }^{1}$ In Indonesia, there is no database on micturition problems even among urologic centers. The urodynamic examination is the gold standard for investigating the pathophysiology of voiding dysfunction, such as urinary incontinence (UI) or lower urinary tract symptoms (LUTS). This procedure can describe disorders in the filling phase and the voiding phase. It measures the intrabladder pressure while evaluating the urinary flow rate during the voiding phase to assess the function of the lower urinary tract and explain the pathophysiology of the patient's complaints. ${ }^{2}$

Javlé et $\mathrm{al}^{3}$ found that urodynamics or pressureflow study has a sensitivity of $87 \%$, a specificity of $93 \%$, and positive predictive value of $95 \%$, respectively in dealing with benign prostate obstruction. Indications for urodynamics study in benign prostatic hyperplasia are men $>80$ years or $<50$ years, post-void residual (PVR) urine $>300 \mathrm{ml}$, maximum urinary flow rate $>10$ 
$\mathrm{ml} / \mathrm{s}$, after radical surgery in pelvic area, previous unsuccessful invasive treatment for LUTS, patients who cannot void $>150 \mathrm{ml}$, or in suspicious neurogenic bladder. ${ }^{4,5}$

Urodynamics often used in the evaluation of LUTS and UI. In LUTS, urodynamics can identify all factors, which contribute to LUTS. It can predict the complications of LUT dysfunction for the upper urinary tract and the outcome of a contemplated treatment. Urodynamics can obtain information about other aspects of LUT function or dysfunction whether expressed as a symptom and confirm the effects of an intervention or understand the mode of action of a particular type of treatment for a LUT dysfunction. ${ }^{6}$ While in UI, urodynamic procedure can show the reason why the previous treatments for UI or LUT dysfunction in general failed. It can also show objectively stress type incontinence, overactive bladder (OAB), a combination of both, LUTS, and bladder atony. ${ }^{6}$

Furthermore, it is necessary to differentiate LUTS, which is caused by bladder outlet obstruction (BOO) or detrusor underactivity (DU) to decide the most suitable treatment. Another indicator in a urodynamic examination is bladder compliance. Normal bladder compliance can compensate for the increase of intrabladder pressure, which was caused by the increasing volume of urine. Low bladder compliance may endanger the upper urinary tract and disturb the filling phase. ${ }^{2}$ Currently, there is no study in Indonesia on a urodynamic profile in a urologic center. Therefore, we believe that this study could become the database for further urodynamic studies in Indonesia.

\section{METHODS}

In this descriptive and retrospective study, patients who underwent a urodynamic examination in the Department of Urology Cipto Mangunkusumo Hospital between July 2010 and August 2015 were included. We retrieved the characteristic of patients, clinical diagnosis before the procedure, urodynamic findings during the filling, and voiding phases from the patient's medical record. This study has been ethically approved by The Ethical Committee of The Faculty of Medicine, Universitas Indonesia with No. 0427/UN2. F1/ETIK/2018.

Characteristics of patients consist of a name, age, gender, and the number of children of adult patients. The clinical diagnosis before urodynamic examinations, are divided into 5 groups: lower urinary tract symptoms, urinary retention, $O A B$, stress incontinence ( $\mathrm{SI})$, and voiding dysfunction in pediatrics. The pediatrics are patients whose age was younger than 18 years old. The capacity of the bladder was divided into three categories: low capacity ( $<250$ CC), normal capacity (250-500 cc), and large capacity (>500 cc).7 Detrusor overactivity (DO) was defined as a urodynamic observation characterized by involuntary detrusor contractions during the filling phase that may be spontaneous or provoked. ${ }^{8} \mathrm{UI}$ is a storage symptom and defined as the complaint of any involuntary loss of urine, whereas urodynamic SI is noted during filling cystometry. Urodynamic SI is defined as the involuntary leakage of urine during raised intravesical pressure secondary to increased abdominal pressure, in the absence of a detrusor contraction. DO incontinence, which also known as urgency $U I$ is the complaint of involuntary leakage with or without preceded by urgency. ${ }^{6}$

This study also describes the urodynamic findings in adult and pediatric patients during the voiding phase. BOO was defined as a generic term for obstruction during voiding and characterized by the increase detrusor pressure and reduce urine flow rate. To assist in determining if $\mathrm{BOO}$ is present, the Indonesian Continence Society (ICS) pressure/flow nomogram can be used to calculate the bladder outlet obstruction index (BOOI). The $\mathrm{BOOI}$ will then categorize patients as being obstructed, unobstructed, or equivocal. DU was a contraction of reduced strength and/or duration, resulting in prolonged bladder emptying and/or a failure to achieve complete bladder emptying within a normal period. Other terms were detrusor sphincter dyssynergia, which defined a detrusor contraction concurrent with an involuntary contraction of the urethral and/or peri-urethral striated muscle. ${ }^{7}$ All data were analyzed using the statistical package for the social sciences software version 21.0.

\section{RESULTS}

There were 1,091 patients who underwent urodynamic examinations between July 2010 and August 2015, which were documented in the urodynamics medical record. All patients were included in this study to get information about their clinical and urodynamic profile. The average number 
of patients who underwent a urodynamic procedure in the Department of Urology Cipto Mangunkusumo Hospital were 218 patients per year or about 17 patients per month with the highest number of registration in the year of $2012(n=238,21.7 \%)$. The average age of patients was 55.6 years old (SD 18.8) with the sociodemographic characteristics described in Table 1. Most patients were males $(n=685,62.7 \%)$, and the patient's age group was $51-60$ years old $(n=243,22.2 \%)$, with the youngest patient is 4 years old and the oldest is 97 years old. The number of adult patients $(n=1,031$, 94\%) was much higher than that of pediatric patients $(n=60,6 \%)$.

Table 1 shows that most clinical diagnoses in the adult group was LUTS ( $n=533,48.9 \%$ ), followed by urinary retention $(n=317,28.9 \%), O A B(n=80,7.3 \%)$, and $\mathrm{SI}(\mathrm{n}=81,7.4 \%)$. Table 2 shows that in the pediatric group, most clinical diagnoses was LUTS $(n=37,3.4 \%)$.

Table 1. Sociodemographic characteristics of urodynamic patients $(n=1,091)$

\begin{tabular}{|c|c|}
\hline Characteristics & $\mathrm{n}(\%)$ \\
\hline \multicolumn{2}{|l|}{ Age (years old) } \\
\hline $0-10$ & $22(2)$ \\
\hline $11-20$ & $51(4.6)$ \\
\hline $21-30$ & $54(4.9)$ \\
\hline $31-40$ & $87(7.9)$ \\
\hline $41-50$ & $142(13.1)$ \\
\hline $51-60$ & $243(22.2)$ \\
\hline $61-70$ & $234(21.5)$ \\
\hline $71-80$ & $200(18.2)$ \\
\hline $81-90$ & $56(5.1)$ \\
\hline $91-100$ & $4(0.4)$ \\
\hline Mean (SD) & $55.6(18.8)$ \\
\hline \multicolumn{2}{|l|}{ Gender } \\
\hline Male & $685(62.7)$ \\
\hline Female & $406(37.3)$ \\
\hline \multicolumn{2}{|l|}{ Number of pediatric patients } \\
\hline Pediatrics ( $\leq 18$ years old) & $60(6)$ \\
\hline Adult (>18 years old) & $1,031(94)$ \\
\hline \multicolumn{2}{|l|}{ Reasons for urodynamics } \\
\hline LUTS & 553 (48.9) \\
\hline Urinary retention & 317 (28.9) \\
\hline SI & $81(7.4)$ \\
\hline $\mathrm{OAB}$ & $80(7.3)$ \\
\hline Pediatrics & $67(6)$ \\
\hline
\end{tabular}

$\mathrm{SD}=$ standard deviation; LUTS=lower urinary tract symptoms; $\mathrm{SI}=$ stress incontinence; $\mathrm{OAB}=$ overactive bladder
This table also shows the number of patients who had a urodynamic examination before receiving any therapy.

Table 3 shows the clinical diagnoses of patients before urodynamics and the objective diagnoses of patients after urodynamics. Among 553 LUTS patients, there were 186 (34\%) low bladder capacity patients, 84 (15\%) DO patients, 180 (33\%) BOO patients, 83 (15\%) DU patients, and 198 (36\%) bladder atony patients. In 317 urinary retention patients, we found 121 (38\%) patients with BOO, 51 (16\%) patients with DU, 95 (30\%) patients with bladder atony, and $48(15 \%)$ patients with a combination of $\mathrm{BOO}$ and $\mathrm{DU}$ as a result of urodynamics. In addition, there were $2(1 \%)$ patients with normal voiding phase urodynamics.

In 80 patients with clinical disorders of $O A B$, there were $51(64 \%)$ patients with DO, 17 (21\%) patients with DO incontinence, and $22(28 \%)$ patients with urodynamic SI as a result of urodynamics. In 81 patients with SI problems, we found 9 (11\%) DO patients, 9 (11\%) DO incontinence patients, and 63 (78\%) urodynamic SI patients from the results of urodynamics. In pediatric patients, there were 37 patients with LUTS, 6 patients with urinary retention, 11 patients with neurological problems, and 6 patients with incontinence disturbance as a pre-urodynamic clinical diagnosis, while the diagnosis after urodynamics is shown in Table 3.

\section{DISCUSSION}

Several studies about urodynamic profiles and the prevalence of voiding disturbances in European, American, and Asian countries have been published for a large proportion of the population. ${ }^{-9}$ Meanwhile in Indonesia, a study documenting urodynamics profiles has not been performed even among urologic centers. Therefore, this study could become the database for further studies on urodynamics.

This study showed that the most common clinical diagnoses of patients who underwent urodynamic examinations both in the adult and pediatric groups was LUTS $(n=553,48.9 \%)$. Previous descriptive studies in other countries also showed similar results. ${ }^{10-12}$ The majority of patients were males $(n=685,62.7 \%)$, and the age group of patients was 51-60 years old $(n=243$, $22.2 \%$ ), which is in line with previous studies by Milsom et al, ${ }^{13}$ Malmsten et al, ${ }^{10}$ and Engstrom et al.."

A survey of urologists in Indonesia showed that $18.6 \%$ of urologists used urodynamic examinations

mji.ui.ac.id 
Table 2. Number of patients according to clinical diagnosis before the urodynamic examination, $\mathrm{n}$ or $\mathrm{n}(\%)$

\begin{tabular}{|c|c|c|c|c|c|c|c|}
\hline Diagnosis & 2010 & 2011 & 2012 & 2013 & 2014 & 2015 & Total \\
\hline \multicolumn{8}{|l|}{ LUTS } \\
\hline Before any treatment & 16 & 36 & 47 & 55 & 26 & 15 & 195 (17.9) \\
\hline$<50$ years old & 17 & 35 & 24 & 21 & 11 & 20 & $128(11.7)$ \\
\hline$>80$ years old & 5 & 3 & 4 & 4 & 3 & 2 & 21 (1.9) \\
\hline Before invasive treatment & 0 & 0 & 0 & 0 & 4 & 0 & $4(0.4)$ \\
\hline Failure of treatment & 0 & 0 & 0 & 1 & 14 & 19 & $34(3.1)$ \\
\hline After invasive treatment & 1 & 4 & 3 & 8 & 15 & 2 & $33(3)$ \\
\hline With suspicious neurogenic bladder & 25 & 29 & 15 & 14 & 22 & 5 & $110(10)$ \\
\hline With bilateral hydronephrosis & 0 & 3 & 2 & 0 & 3 & 4 & $12(1)$ \\
\hline PVR $>150 \mathrm{ml}$ & 6 & 2 & 1 & 6 & 1 & 0 & $16(1.5)$ \\
\hline Total & $70(6.3)$ & $112(10.2)$ & $96(8.8)$ & $109(9.94)$ & $99(9.02)$ & $67(6.1)$ & $553(48.9)$ \\
\hline \multicolumn{8}{|l|}{ Urinary retention } \\
\hline Before any treatment & 10 & 36 & 25 & 22 & 15 & 13 & $121(11)$ \\
\hline$<50$ years old & 2 & 7 & 6 & 3 & 6 & 4 & $28(2.6)$ \\
\hline$>80$ years old & 2 & 1 & 3 & 1 & 6 & 2 & $15(1.4)$ \\
\hline Before invasive treatment & 0 & 0 & 0 & 0 & 0 & 1 & $1(0.1)$ \\
\hline After invasive treatment & 0 & 2 & 7 & 2 & 8 & 2 & $21(1.9)$ \\
\hline With suspicious neurogenic bladder & 2 & 23 & 46 & 24 & 28 & 8 & 131 (11.9) \\
\hline Total & $16(1.5)$ & $69(6.3)$ & $87(7.9)$ & $52(4.7)$ & $63(5.7)$ & $30(2.7)$ & $317(28.9)$ \\
\hline \multicolumn{8}{|l|}{ OAB } \\
\hline Before any treatment & 5 & 4 & 10 & 11 & 3 & 9 & $42(3.8)$ \\
\hline Failure of treatment & 0 & 0 & 0 & 0 & 7 & 3 & $10(0.9)$ \\
\hline $\mathrm{OAB}+\mathrm{SI}$ (mixed incontinence) & 2 & 3 & 6 & 6 & 4 & 3 & $24(2.2)$ \\
\hline With invasive treatment scheduled & 0 & 0 & 1 & 0 & 3 & 0 & $4(0.4)$ \\
\hline Caused by invasive treatment & 0 & 0 & 0 & 0 & 0 & 0 & $0(0)$ \\
\hline Total & $7(0.6)$ & $7(0.6)$ & $17(1.6)$ & $17(1.6)$ & $17(1.6)$ & $15(1.4)$ & $80(7.3)$ \\
\hline \multicolumn{8}{|l|}{ SI } \\
\hline Before any treatment & 6 & 19 & 15 & 8 & 5 & 5 & $58(5.3)$ \\
\hline Before invasive treatment & 0 & 0 & 2 & 0 & 1 & 0 & $3(0.3)$ \\
\hline $\mathrm{SI}+\mathrm{OAB}$ (mixed incontinence) & 0 & 2 & 3 & 1 & 1 & 0 & $7(0.6)$ \\
\hline Failure of treatment & 0 & 0 & 3 & 0 & 7 & 3 & $13(1.2)$ \\
\hline Total & $6(0.5)$ & $21(1.9)$ & $23(2.1)$ & $9(0.8)$ & $14(1.3)$ & $8(0.7)$ & $81(7.4)$ \\
\hline \multicolumn{8}{|l|}{ Pediatrics } \\
\hline With LUTS & 3 & 8 & 9 & 5 & 4 & 8 & $37(3.4)$ \\
\hline With urinary retention & 0 & 2 & 0 & 2 & 1 & 1 & $6(0.6)$ \\
\hline With neurologic problems & 0 & 4 & 4 & 0 & 2 & 1 & $11(1)$ \\
\hline With incontinence disturbance & 0 & 2 & 2 & 2 & 1 & 1 & $6(0.6)$ \\
\hline Total & $3(0.3)$ & $16(1.5)$ & $15(1.4)$ & $9(0.8)$ & $8(1.1)$ & $11(1)$ & $60(6)$ \\
\hline Total of all cases per year & $102(9.3)$ & $225(20.5)$ & $238(21.7)$ & $196(17.9)$ & $201(18.7)$ & $131(11.9)$ & $1091(100)$ \\
\hline
\end{tabular}




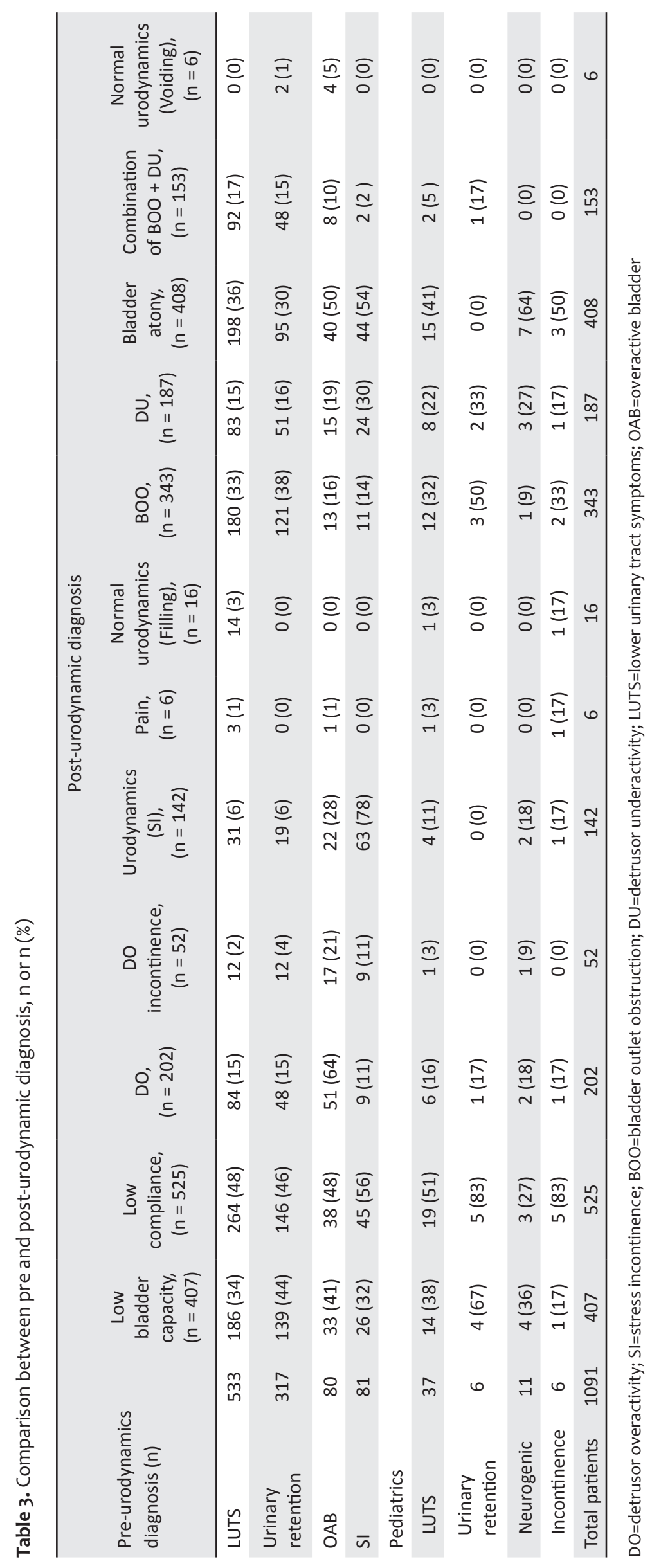


as a diagnostic tool to diagnose $O A B$ before providing any treatment, and $33.3 \%$ used it as an additional examination when initial therapy has failed. ${ }^{14}$ However, there is a discrepancy in this study since only $3.8 \%$ of $O A B$ cases were sent to undergo urodynamics before any treatment, and only $0.9 \%$ of cases of $O A B$ treatment failures underwent urodynamic examinations. It differs from the European Association of Urology (EAU) Guidelines, which state that a pressure flow study is offered if conservative treatment has failed, and no indication for a patient who has not received any treatment. ${ }^{4}$

According to the ICS Guidelines, urodynamic examinations were indicated for patients with any problem with urination who need objective pathophysiological confirmation and to evaluate its etiology. Patients with UI with complications, such as recurrent UI or UI accompanied by pain, hematuria, recurrent urinary tract infection, voiding and storage problems, prostate irritation, and radical pelvic operation, should be referred to a specialist; a urodynamic examination is recommended for patients with suspicious $O A B$ or incompetence of the sphincter. ${ }^{15}$ These indications contradicted the data presented in this study which showed that some patients undergone urodynamic examination before the treatment started (OAB 42 [3.8\%], LUTS 195 [17.8\%], and urinary retention $121[11 \%])$. It is essential that a clinician carefully select patients who need to undergo urodynamic examination based on the guidelines.

This study categorized LUTS and UI based on the clinical situation and includes men $<50$ years old and $>80$ years old, before and after invasive treatment, suspicious neurogenic bladder, and PVR $>150 \mathrm{ml}$. This categorization was suitable with the EAU and Ikatan Ahli Urologi Indonesia (IAUI) guideline on the management of non-neurogenic male LUTS. ${ }^{4,5}$ González Ruiz et $\mathrm{al}^{16}$ found that in 300 patients with voiding disturbances at the two biggest urodynamic centers in England, 75\% of patients had BOO and 25\% had DU. Similar results were found in this study. Earlier prevalence studies investigated the frequency of voiding problems, such as UI, hesitancy, weak urinary stream, dribbling, the sensation of incompletely emptied bladder, and nocturia, grouped according to age, whereas this study assessed the symptoms objectively using a urodynamics machine, and then grouped them according to pediatric or adult categories. ${ }^{10}$
In patients with LUTS and retention, the number of patients with $\mathrm{BOO}$ is less than the number of patients with impaired bladder contraction function (DU and bladder atony). From the results of the urodynamic examination in patients with LUTS, the authirs found 180 (33\%) patients with BOO and 281 (51\%) patients with bladder contraction disorders (DU + bladder atony). In contrast, in urinary retention patients, we found 121 (38\%) patients with BOO and 146 (46\%) patients with bladder contraction disorders. Therefore, the management of patients with LUTS or urinary retention that consists of impaired bladder contraction function cannot be solely treated as only BOO cases but should be treated as bladder contraction disorders. This treatment approach showed the importance of the urodynamic examination in LUTS and retention patients when the patient was indicated.

In this study, 140 (32\%) of LUTS and retention patients had a combination of BOO and DU problems. These patients have a risk of LUTS or urinary retention, even though their obstructive problems have been eliminated. For patients with these kinds of urodynamic results, a good explanation needs to be provided to them. Patients need to know that there is still a risk of voiding disorders even though the obstructive problem has been removed; this is due to bladder contraction disorder. Rademakers et $\mathrm{al}^{17}$ in their study concluded that patients with DU have an unfavorable outcome after prostatic surgery; therefore, preoperative differentiation between DU and BOO seems crucial. The wide range of LUTS makes it difficult to predict DU based only on symptoms, especially if patients have both DU and BOO. Currently, the only tool to diagnose DU safely, with or without BOO, are pressure flow studies. This data is expected to be a consideration in providing more holistic and comprehensive therapy for patients with a combination of DU and BOO problems.

On the other hand, in patients with a clinical diagnosis of LUTS and urinary retention after urodynamic examination, the authors found filling phase problems, such as DO or DO incontinence, urodynamic stress incontinence, and a normal urodynamic voiding phase. The problem of contraction of the bladder it self can also be caused by primary causes, such as neurological or metabolic factors that are underlying the problem. However, it can also be due to the long-standing obstruction that causes 
interference in bladder contractions and other filling phase disorders. This possibility demonstrates the important role of urodynamic examination in LUTS and urinary retention patients.

In this study, it can be seen that not all $O A B$ patients were $D O$ after undergoing urodynamics. Only 51 (64\%) patients among 80 OAB patients had DO because of urodynamics, and 17 (21\%) of them showed DO incontinence. These results are similar to those of the Fan et $a^{18}{ }^{18}$ study that showed only 80 (60.2\%) patients were diagnosed with DO among $133 \mathrm{OAB}$ patients. This could have happened because $O A B$ complaints could also be induced not only by involuntary contraction of the bladder itself but also be influenced by the capacity of the bladder. For example, patients with a small bladder capacity will have an earlier first desire to void. Another study came to a similar conclusion and said the bladder volume at the first desire to void and cystometric capacity were lower in patients diagnosed with OAB..$^{18}$

It is also interesting that among $O A B$ patients, there were 22 (28\%) patients had urodynamic SI result, Al-Ghazo et $\mathrm{al}^{19}$ found similar results in their study regarding the relationship between urodynamic DO and $O A B$ symptoms in men and women. They found the overall incidence of DO was $76.1 \%$ (89 patients) and $58.7 \%$ (54 patients) in male and female $O A B$ patients, respectively, $58 \%$ of women had stress UI symptoms with $26.4 \%$ having urodynamic SI. This finding might be due to an incorrect clinical diagnosis before urodynamics or because of the presence of a mixed incontinence component in those patients. Therefore, the use of urodynamics to differentiate whether clinical complaints of $O A B$ are DO or there is a mixed component with SI were needed. The results also can answer why $O A B$ patients often did not improve with antimuscarinic treatment because there was a mixed component of $\mathrm{SI}$ in it. It also showed the important role of urodynamics examination in $O A B$ patients.

From 81 patients with a clinical diagnosis of $\mathrm{SI}$, we found $63(78 \%)$ patients with urodynamic SI, 9 (11\%) patients with DO, and $9(11 \%)$ patients with DO incontinence. Colli et a ${ }^{20}$ performed a literature review including 5,192 women with incontinence from 23 studies to identify how well incontinence symptoms related to urodynamic findings; the sensitivity was $82 \%$ for stress UI. The results of this study are close to theirs and showed the important role of urodynamic examinations in SI patients.

Another interesting thing from the results of this study is that patients with clinical diagnoses of $O A B$ and $\mathrm{SI}$ after urodynamic examinations had voiding phase problems, such as BOO, DU, bladder atony, normal urodynamics, and a combination of $\mathrm{BOO}$ and DU. In OAB patients, there were $13(16 \%)$ patients with BOO, 15 (19\%) patients with DU, 40 (50\%) patients with bladder atony, 4 (5\%) patients with normal urodynamic voiding phase, and $8(10 \%)$ patients with a combination of $\mathrm{BOO}$ and DU. These problems can be due to a long-standing obstruction that causes interference in bladder contractions and other filling phase disorders. Therefore, antimuscarinic administration to $O A B$ patients, who also have voiding problems, must be more careful because it will increase the risk of LUTS, or even urinary retention. Thus, it is important to consider providing therapy with beta 3 agonists in this type of patient. The drug facilitates detrusor relaxation during the storage phase of micturition and improves the storage capacity of the bladder without impairing contraction during the voiding phase. This drug represents new hope, particularly for patients who do not respond adequately to or cannot tolerate, and who are not candidates for antimuscarinic therapy. ${ }^{21}$

In SI patients, there were 11 (14\%) patients with BOO, 24 (30\%) patients with DU, 44 (54\%) patients with bladder atony, and $2(2 \%)$ patients with a combination of BOO and DU. This result showed that it is better when treating a SI patient to assess whether the patient also has a voiding disorder or not, to obtain optimal treatment results. For instance, treating SI patients that have voiding problems must be considered, especially if they plan to undergo urethral sling surgery. This suggestion shows the important role of urodynamic examinations in both $\mathrm{OAB}$ and $\mathrm{SI}$ patients with concomitant voiding problems.

In $60(6 \%)$ of pediatric patients, most LUTS and urinary retention were caused by impaired bladder contraction (DU in 10 patients [16.7\%] and bladder atony in 15 patients [25\%]), while BOO was only in 15 patients (25\%). These results are similar to those of another study that showed the most commonly diagnosed patients after urodynamics were unstable bladder dysfunction ( $n=152,31 \%$ ), and neurogenic bladder dysfunction ( $\mathrm{n}=35,7 \%$ ), whereas $\mathrm{BOO}$ was only in $22(4 \%)$ subjects. ${ }^{22}$ 


\section{Conclusions}

This study shows that there are patients with voiding disorders who are immediately subjected to urodynamic examination without being treated first. The clinician must carefully select the patient who needs to undergno a urodynamic examination based on the guidelines. This study also demonstrates both the role and superiority of urodynamics in diagnosing patients with voiding disorders, especially when the disorders have mixed components. Finally, urodynamics played important roles in detecting urinary problems at Cipto Mangunkusumo Hospital.

\section{Conflict of Interest}

Harrina Erlianti Rahardjo is one of the editorial board members but was not involved in the review or decision process of the article.

\section{Acknowledgment}

None.

Funding Sources

None.

\section{REFERENCES}

1. Boyle P, Robertson C, Mazzetta C, Keech M, Hobbs FD, Fourcade $\mathrm{R}$, et $\mathrm{al}$. The prevalence of lower urinary tract symptoms in men and women in four centres. The UrEpik study. BJU Int. 2003;92(4):409-14.

2. Nitti VW. Pressure flow urodynamic studies: the gold standard for diagnosing bladder outlet obstruction. Rev Urol. 2005;7(Suppl 6):S14-21.

3. Javlé $P$, Jenkins SA, Machin DG, Parsons KF. Grading of benign prostatic obstruction can predict the outcome of transurethral prostatectomy. J Urol. 1998;160(5):1713-7.

4. Gravas S, Bachmann A, Descazeaud A, Drake M, Gratzke C, Madersbacher $S$, et al. Guidelines on the management of nonneurogenic male lower urinary tract symptoms (LUTS), incl. benign prostatic obstruction (BPO). European Association of Urology [online], 2015.

5. Hardjowijoto S, Taher A, Poernomo B, Umbas R, Sugandi S, Rahardjo D. Pedoman penatalaksanaan BPH di Indonesia. Surabaya: IAUI, 2015.

6. Abrams P, Cardozo L, Khoury S, Wein A. Incontinence: 5 th International Consultation on Incontinence, Paris, February 2012. ICUD-EAU, 2013.

7. Irwin DE, Milsom I, Hunskaar S, Reilly K, Kopp Z, Herschorn S, et al. Population-based survey of urinary incontinence, overactive bladder, and other lower urinary tract symptoms in five countries: results of the EPIC study. Eur Urol 2006;50(6):1306-14.
8. Stewart WF, Van Rooyen JB, Cundiff GW, Abrams P, Herzog AR, Corey $\mathrm{R}$, et al. Prevalence and burden of overactive bladder in the United States. World J Urol. 2003;20(6):327-36.

9. Homma Y, Yamaguchi O, Hayashi K, Neurogenic Bladder Society Committee. An epidemiological survey of overactive bladder symptoms in Japan. BJU Int 2005;96(9):1314-8.

10. Malmsten UG, Milsom I, Molander U, Norlén LJ. Urinary incontinence and lower urinary tract symptoms: an epidemiological study of men aged 45 to 99 years. J Urol. 1997;158(5):1733-7.

11. Engström G, Walker-Engström ML, Lööf L, Leppert J. Prevalence of three lower urinary tract symptoms in men-a populationbased study. Fam Pract. 2003;20(1):7-10.

12. Coyne KS, Sexton CC, Bell JA, Thompson CL, Dmochowski $\mathrm{R}$, Bavendam $\mathrm{T}$, et al. The prevalence of lower urinary tract symptoms (LUTS) and overactive bladder (OAB) by racial/ethnic group and age: results from OAB-POLL. Neurourol Urodyn. 2013;32(3):230-7.

13. Milsom I, Abrams P, Cardozo L, Roberts RG, Thüroff J, Wein AJ. How widespread are the symptoms of an overactive bladder and how are they managed? A population-based prevalence study. BJU Int. 2001;87(9):760-6.

14. Tirtayasa PM, Rahardjo HE. A survey on the management of overactive bladder by Indonesian urologists. Med J Indones. 2015;24(2):91-6.

15. Rahardjo HE, Santoso BI, Hakim S, Hasan B, Tjahjodjati, Moegni F. Inkontinensia urin pada usia lanjut. In: Rahardjo HE. Panduan tata laksana inkontinensia urin pada dewasa. Jakarta: Perkumpulan Kontinensia Indonesia (PERKINA). 2018;36-55.

16. González Ruiz MI, Flores Carreras O, Velázquez Castellanos PI, Martínez Espinoza CJ, Márquez Allegre R, Aquino Hernández JL. "[Prevalence and clinical-urodynamic characteristics of vesical voiding dysfunction in two urodynamic centres]." Ginecol Obstet Mex. 2005;73(11):596-603.

17. Rademakers KL, van Koeveringe GA, Oelke M. Detrusor underactivity in men with lower urinary tract symptoms/benign prostatic obstruction: characterization and potential impact on indications for surgical treatment of the prostate. Curr Opin Urol. 2016;26(1):3-10.

18. Fan YH, Lin CC, Lin AT, Chen KK. Are patients with the symptoms of overactive bladder and urodynamic detrusor overactivity different from those with overactive bladder but not detrusor overactivity? J Chin Med Assoc. 2011;74(10):455-9.

19. Al-Ghazo MA, Ghalayini IF, Al-Azab R, Hani OB, Matani YS, Haddad $Y$, et al. Urodynamic detrusor overactivity in patients with overactive bladder symptoms. Int Neurourol J. 2011;15(1):48-54.

20. Colli E, Artibani W, Goka J, Parazzini F, Wein AJ. Are urodynamic tests useful tools for the initial conservative management of non-neurogenic urinary incontinence? a review of the literature. Eur Urol. 2003;43(1):63-9.

21. Aditya S, Mathur SK. Mirabegron: a first-in-class beta-3 agonist for overactive bladder. J Mahatma Gandhi Inst Med Sci. 2015;20(2):128-33.

22. Szabó L, Lombay B, Borbás E, Bajusz I. Videourodynamics in the diagnosis of urinary tract abnormalities in a single center. Pediatr Nephrol. 2004;19(3):326-331. 